\title{
Simulation of Downlink of 10G-PON FTTH in the city of Košice
}

\author{
$1^{\text {st }}$ Tomáš Huszaník \\ Department of Electronics and \\ Multimedia Communications, \\ Faculty of Electrical Engineering and \\ Informatics, Technical University of \\ Košice, \\ Košice, Slovakia \\ tomas.huszanik@tuke.sk
}

\author{
$2^{\text {nd }}$ Ján Turán \\ Department of Electronics and \\ Multimedia Communications, \\ Faculty of Electrical Engineering and \\ Informatics, Technical University of \\ Košice, \\ Košice, Slovakia \\ jan.turan@tuke.sk
}

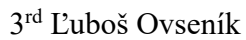 \\ Department of Electronics and \\ Multimedia Communications, \\ Faculty of Electrical Engineering and \\ Informatics, Technical University of \\ Košice, \\ Košice, Slovakia \\ lubos.ovsenik@tuke.sk
}

\begin{abstract}
Optical fiber has the great advantages of capacity and reliability. That is why network providers started to deploy FTTx (Fiber-To-The-x) optical access using various PON (Passive Optical Network) architectures. The leading technology right now is Gigabit PON (GPON). However, with increasing amount of multimedia we need to further develop existing technologies to go on with these high demands. Fiber-To-The-Home (FTTH) using 10G-PON technology for broadband access application is effective solution for high speed networks with high capacity. In this paper, we look at the passive optical network in the city of Košice and based on the real network we created simulation model of downlink of 10G-PON based FTTH with triple-play service.
\end{abstract}

Keywords-10G-PON, FTTH, OptSim, OTDR, passive optical network.

\section{INTRODUCTION}

Optical networks have grown rapidly in past few years. The Internet has produced high demands for broadband services. This led to the extensive growth of IP (Internet Protocol) data transmission which means that service providers had to upgrade their existing networks. At present, we are seeing everincreasing demands on data transmission, whether via cable lines or wireless transmission. One of the most important events in telecommunications was the introduction of optics into the data transmission concept. Optics have brought a new and more promising way of communicating, increasing the amount of data transmitted, increasing transmission speed, providing faster, better quality and scalable services that are accessible to a large number of end users. Compared to a metallic conductor cable optical fiber has several advantages, including larger bandwidth, greater security of data transmission, smaller operating dimensions, and hence smaller weight and one of the most important advantages is ability to transmit information over long distances. Because of its versatility and almost unlimited bandwidth, optical fiber becomes an ideal transfer medium [1], [2].

Optical access network (OAN) is a network distribution infrastructure that mediates connectivity between the end user and the network (telecommunication service provider) through optical fiber. Until recently, fiber-optic technologies have been used exclusively in backbone and metropolitan networks [3]. However, thanks to their performance - price and capacity enhancement capabilities, they have become the standard for access networks.

In this paper we analyzed a real Ethernet-PON in the city of Košice using optical time domain reflectometry. Using results from optical reflectometry, we built corresponding downlink simulation model. The experimental results are presented in form of BER and Q factor analysis.

\section{OVERVIEW ON TECHNOLOGY DESCRIPTION}

PON represents the optical distribution network (ODN) between optical line terminal (OLT) and optical network units (ONUs) and does not contain any active electronic devices but instead uses connectors and optical splitters to direct the signals of individual wavelengths to end users. Optical splitters can share network transmission capacity for up to 256 end-users in uplink and downlink data streams. A disadvantage over active optical networks (AON) is that PON networks only share (divide) the given optical signal without any intervention or modification. The term "intervention" or "modification" means signal amplification using optical amplifiers, or signal regeneration by optical repeaters. These components are listed as active. Theoretically, an optical signal in PON networks can only be propagated within $20 \mathrm{~km}$, while AON networks can cover a distance of approximately $100 \mathrm{~km}$. This means that with AON networks, end users may be further away from the signal source [3-5].

Most of the recently deployed PONs in Europe are based on Gigabit PON (GPON) standardized by G.984 recommendation by ITU-T. The latest generation of broadband passive optical access standard G.984.7 was ratified in 2010. Within the GPON technology, we can reach up to $2.488 \mathrm{Gbps}$ in the downstream direction at $1480 \mathrm{~nm}$, the transmission speed in the upstream direction is around $1.244 \mathrm{Gbps}$ at $1310 \mathrm{~nm}$. GPON provides a full quality of service assurance (QoS), asynchronous transfer mode (ATM) and the Gigabit-capable Passive Optical Network Encapsulation Method (GEM) [4]. The principle of the GEM method is based on encapsulation of the data of characteristic GPON frames. The result of data encapsulation is that the end- 
user can use provided services, such as IPTV (Internet Protocol Television), video on demand (VoD), Internet, voice or data transmission [5].

Ethernet Passive Optical Network (E-PON) is a technology based on the 802.3ah specification of the Institute of Electrical and Electronic Engineers (IEEE). EPON network is sometimes used to be referred to as Ethernet in first mile fiber (EFMF). The principle of EPON is based on this concept, so that Ethernet cable can be introduced to end users up to a maximum of $20 \mathrm{~km}$ form the source. The transfer rate in symmetrical case in practice is $1.25 \mathrm{Gbps}$. EPON is fully compatible with other standards using Ethernet. Therefore, no conversion and encapsulation with the GEM method is required after connecting to the EPON [3-5].

The 10 Gbps Passive Optical Network (10G-PON) is the next-generation passive optical network technology. Today we can choose from two possible configurations - asymmetric and symmetric. Asymmetric configuration is standardized by IEEE 802.3av (XGS-PON) and increases the data rate of EPON form $1.25 \mathrm{Gbps}$ to $10 \mathrm{Gbps}$ in downstream direction. Transmission rate in upstream direction stays at $1.25 \mathrm{Gbps}$. In the symmetrical configuration, characterized by ITU-T G.987 (10-Gigabitcapable passive optical network (XG-PON) systems), transmission rate in downstream and upstream direction is 10 Gbps. The configuration of XG-PON enables the coexistence of 10G-PON and GPON using wavelength selective filters. The latest architecture developed for 10G-PON is NG-PON2 (2015) which is capable of supporting multiple channels with maximum of $40 \mathrm{Gbps}$ data rate. Unfortunately, there is still debate on the best architecture to be deployed for 10G-PON [3-6].

\section{ANALYSIS OF PON IN THE CITY OF KoŠICE}

The construction of the PON network connecting Košice and Lorinčík was completed in 2008. The network connects the local Internet connection provider based in Košice on the Čarska Street and the city district Lorinčík. Later, based on the citizens' initiative, the connection provider connected the city district on the optical network. During the first phase of construction, only the local office in Lorinčík joined the optical network. In the next stages of implementation of the PON network in this area, other end-users joined the optical network. The geographical distribution of the PON network is shown in Fig. 1.

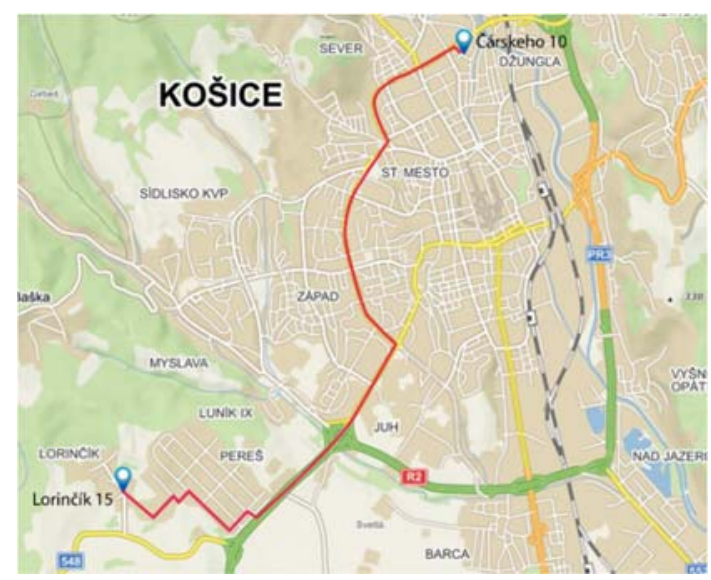

Fig. 1. The geographical distribution of PON Košice - Lorinčík
Using optical time domain reflectometry (OTDR) we obtained a backscatter curve at a logarithmic scale and a table with values corresponding to the events in this specific optical path. Optical distribution network (ODN) of PON network interconnecting Košice nad Lorinčík was tested using optical time domain reflectometry (OTDR) so that the real results can be impleneted to the simulation model which is later described. OTDR device used for this purpose was EXFO FTB-200. The reflection curve of PON between Košice and Lorinčík is in Fig. 2.

One of the most important parameters of each optical network is attenuation on the optical path, which can be characterized by the following well known relationship:

$$
A=10 \log \left(\frac{P_{\text {in }}}{P_{\text {out }}}\right)[d B],
$$

where $P_{\text {in }}$ is the input power and $P_{\text {out }}$ is the output power [1]. The attenuation rate expressed per unit length is determined as:

$$
\alpha=\frac{1}{L} 10 \log \left(\frac{P_{\text {in }}}{P_{\text {out }}}\right)[\mathrm{dB} / \mathrm{km}],
$$

Then, the power at the end of the optical path is expressed as:

$$
P_{\text {out }}=P_{\text {in }} 10^{\frac{-\alpha L}{10}}=P_{\text {in }} 10^{\frac{-A(d B)}{10}}[W] \text {. }
$$

The overall attenuation on the optical path is determined by the sum of the attenuations created on the fiber itself, connectors and welds [1]. The attenuation budget of PON network between Košice and Lorinčík is following:

- Single Mode Fiber G.652.D - $0.3 \mathrm{~dB} / \mathrm{km}$,

- $\mathrm{SC} / \mathrm{APC}$ connectors $-0.3 \mathrm{~dB}$,

- $\mathrm{AWG}$ (Arrayed Waveguide) $-4 \mathrm{~dB}$,

- Optical Line Terminal (OLT) - maximum transmitting power - $5.5 \mathrm{dBm}(3.55 \mathrm{~mW})$,

- $\quad$ Optical Network Unit (ONU) - maximum transmitting power $-8 \mathrm{dBm}(0.16 \mathrm{~mW})$.

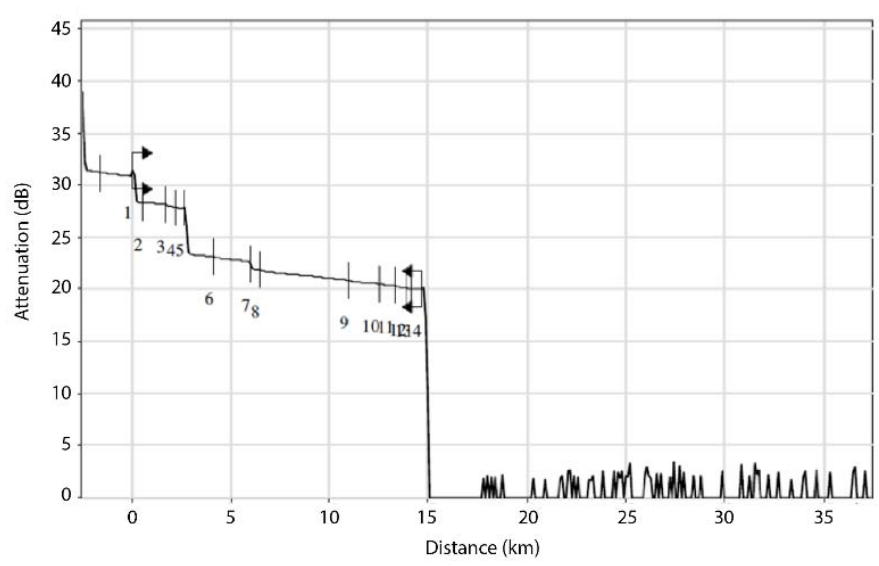

Fig. 2. The reflection curve of PON between Košice and Lorinčík 
Total optical fiber loss is $8.411 \mathrm{~dB}$, with an average fiber attenuation of $0.572 \mathrm{~dB} / \mathrm{km}$. The total length of the evaluated singlemode optical fiber with a core diameter of $9 \mu \mathrm{m}$ was $14.708 \mathrm{~km}$, the evaluation time was 30 seconds and a test impulse width was $1 \mu \mathrm{s}$. The OTDR has recorded 14 sections (see figure 2.) that correspond to different types of phenomena. The individual loss values in a given PON network and their exact location are recorded in Table I.

TABLE I. THE REAL VALUES OF PON FORM OTDR

\begin{tabular}{|c|c|c|c|c|}
\hline Section & $\begin{array}{c}\text { Distance } \\
(\mathbf{k m})\end{array}$ & Type of phenomena & $\begin{array}{l}\text { Loss } \\
\text { (dB) }\end{array}$ & $\begin{array}{c}\text { Cumulation } \\
\text { (dB) }\end{array}$ \\
\hline \multirow{2}{*}{1} & \multirow{2}{*}{0,000} & Measurement start & 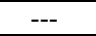 & 0.000 \\
\hline & & SMF $(0.531 \mathrm{~km})$ & 0.113 & 0.113 \\
\hline \multirow{2}{*}{2} & \multirow{2}{*}{0.531} & Reflection & -0.063 & 0.050 \\
\hline & & SMF (1.955 km) & 0.230 & 0.279 \\
\hline \multirow{2}{*}{3} & \multirow{2}{*}{1.726} & No reflection & 0.192 & 0.472 \\
\hline & & SMF $(0.467 \mathrm{~km})$ & 0.090 & 0.562 \\
\hline \multirow{2}{*}{4} & \multirow{2}{*}{2.195} & No reflection & 0.048 & 0.610 \\
\hline & & SMF $(0.463 \mathrm{~km})$ & 0.100 & 0.710 \\
\hline \multirow{2}{*}{5} & \multirow{2}{*}{2.657} & Refelection & 4.300 & 5.010 \\
\hline & & SMF (1.472 km) & 0.308 & 5.318 \\
\hline \multirow{2}{*}{6} & \multirow{2}{*}{4.129} & No reflection & 0.065 & 5.383 \\
\hline & & SMF $(1.815 \mathrm{~km})$ & 0.396 & 5.779 \\
\hline \multirow{2}{*}{7} & \multirow{2}{*}{5.945} & No reflection & 0.676 & 6.454 \\
\hline & & SMF $(0.527 \mathrm{~km})$ & 0.114 & 6.568 \\
\hline \multirow{2}{*}{8} & \multirow{2}{*}{6.473} & No reflection & 0.101 & 6.669 \\
\hline & & SMF (4.510 km) & 0.872 & 7.541 \\
\hline \multirow{2}{*}{9} & \multirow{2}{*}{10.983} & No reflection & 0.083 & 7.624 \\
\hline & & SMF $(1.553 \mathrm{~km})$ & 0.268 & 7.892 \\
\hline \multirow{2}{*}{10} & \multirow{2}{*}{12.536} & No reflection & 0.034 & 7.926 \\
\hline & & SMF (0.793 km) & 0.161 & 8.087 \\
\hline \multirow{2}{*}{11} & \multirow{2}{*}{13.329} & No reflection & 0.068 & 8.155 \\
\hline & & SMF (0.541 km) & 0.103 & 8.258 \\
\hline \multirow{2}{*}{12} & \multirow{2}{*}{13.869} & No reflection & 0.053 & 8.312 \\
\hline & & SMF $(0.281 \mathrm{~km})$ & 0.055 & 8.367 \\
\hline \multirow{2}{*}{13} & \multirow{2}{*}{14.151} & Reflection & -0.071 & 8.296 \\
\hline & & SMF $(0.557 \mathrm{~km})$ & 0.115 & 8.411 \\
\hline 14 & 14.708 & $\begin{array}{l}\text { Fresnel's reflection } \\
\text { from the end of the } \\
\text { SMF }\end{array}$ & --- & 8.411 \\
\hline
\end{tabular}

The current PON between Košice and Lorinčík deploy E-PON (Ethernet PON) that delivers maximum 1 Gbps symmetrical bandwidth. According to the local provider, the network would be sufficient to support G-PON and hypothetically 10G-PON.

\section{THE SIMULATION MODEL OF 10G-PON FTTH SYSTEM}

OptSim, from the company RSoft, is a professional simulation software that is used for advanced simulation of fiber optic and wireless-optic communication systems. OptSim has found its application not only in the industrial but also academic fields. OptSim enables the design and simulation of DWDM and CWDM systems using optical amplifiers. OptSim is also used for passive and active fiber optic designs or for optical networks designed for cable television networks. Simulation in OptSim is based on block theory. This means that every component in the network, respectively subnet or subsystem in the network is represented by one block. The simulation runs independently of blocks. Advantages of this program that we can include are - ability to import Matlab files, optimizing designs, or testing optical communication systems before they are implemented in practice. The downside is that OptSim does not support measuring optical communication systems with OTDR devices [6-9].

Passive optical network (PON), as standardized by International Telecommunication Union (ITU), provides broadband services to end users through the optical fiber access. The major advantage of passive network over active one is the lack of active network components which significantly reduce the cost of the solution. PON architectures are mainly used in fiber to the home (FTTH) technologies. FTTH infrastructure can carry multiple services - plain old telephony service (POTS), voice over IP (VoIP), video, data and telemetry data [1], [4].

The simulation model of 10G-PON FTTH system is shown in Fig. 3. The simulation model consists of three parts - central office (CO), optical distribution network (ODN) and optical network terminals (ONTs). Central office is located at provider's site controlling the bidirectional flow of data across the optical distribution network. Our central office contains two wavelength channels. The first channel, operating at $1480 \mathrm{~nm}$, provides $10 \mathrm{Gbps}$ data stream. This channel corresponds to the Internet and VoIP service. In this case, this channel uses NRZOOK modulation and transmitting power is set to $-10 \mathrm{dBm}$ $(0.1 \mathrm{~mW})$. The second channel is there to simulate $10 \mathrm{Gbps}$ video broadcasting. In PONs, cable television is often broadcasted on $1550 \mathrm{~nm}$ wavelength. It is so in this case as well. These two channels represent sought after triple-play service (Internet+VoIP+CATV). The two channels are then multiplexed and amplified via EDFA (Erbium Doped Fiber Amplifier) to the desired level.

Optical distribution network (ODN) is based on the real optical path between Košice and Lorinčík. The attenuation value of the real ODN is $8.411 \mathrm{~dB}$ (measured via OTDR). The attenuation of the simulated ODN is $9.832 \mathrm{~dB}$ which is approximately $1.4 \mathrm{~dB}$ more than the real ODN. The difference is due to the presence of SC/APC optical connectors with an insertion loss of $0.5 \mathrm{~dB}$ and that the OptSim does not support optical line testing using the OTDR (when testing with OTDR, there is a reflection from the OTDR's connector which could not be simulated in OptSim).

At the end of the ODN, there is a passive splitter that splits the signal to multiple optical network terminals (ONTs). ONT is placed directly at end users home (or office). The main purpose of ONT is to provide optical connection to ODN. ONT supports various services including Ethernet rates $\mathrm{T} 1$ or E1 (1.544 or $2.048 \mathrm{Mbps}$ ) and E3 or DS3 (33.368 or $44.736 \mathrm{Mbps})$ telephone connections, ATM interfaces (155 Mbps), 2.4 and $5 \mathrm{Ghz} \mathrm{WiFi}$, and digital and analog video formats. In our 10GPON FTTH system we simulate only one ONT. Signals received by ONT 1 are then analyzed and discussed in the following sections of this paper.

The aim of the simulation is to provide the experimental results of the 10G-PON standard so that it can be applicable to a specific network. Presented simulation model of 10G-PON FTTH system provides only downlink simulation. 


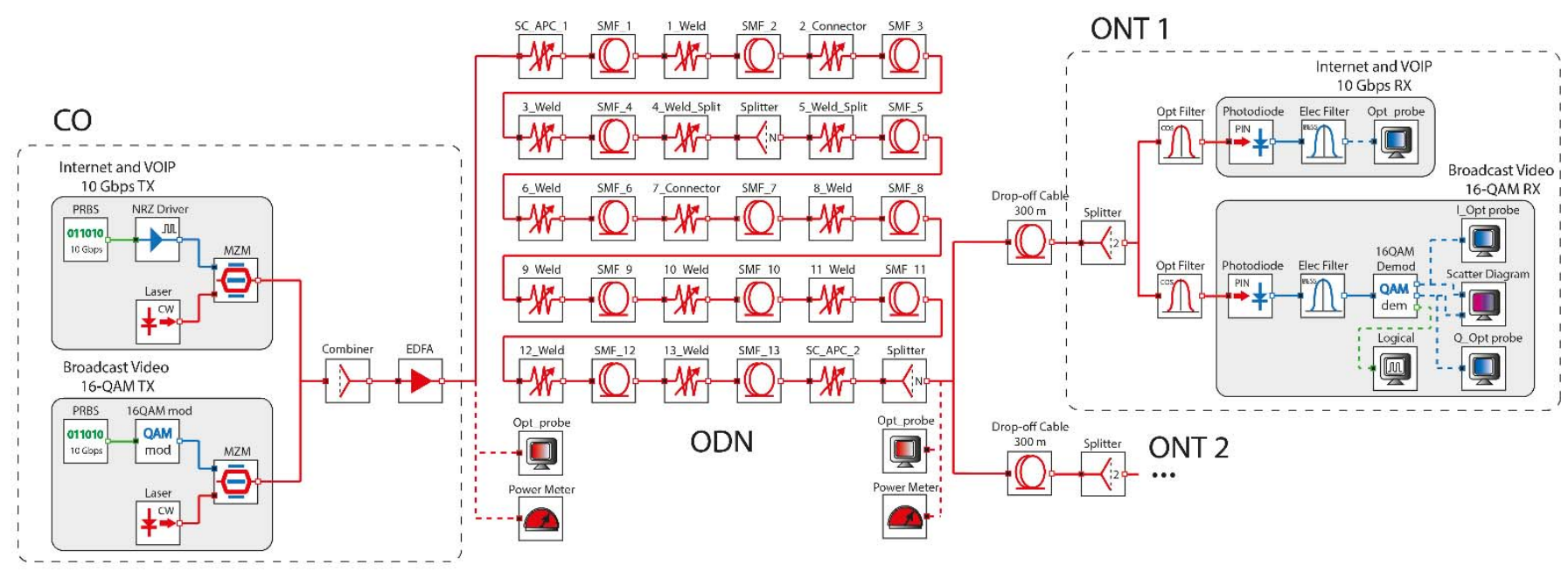

Fig. 3. Simulation model of 10G-PON FTTH system

\section{RESULTS AND DISCUSSION}

The simulation of 10G-PON based FTTH with triple play service is divided into two parts. In the first part, we tested four optical modulation techniques as shown in Fig. 4 - NRZ-OOK (Non-Return-to-Zero On-Off Keying), optical duobinary modulation, two state NRZ-DPSK (Non-Return-to-Zero Differential Phase Shift Keying) and two state CRZ-DPSK (Chirp-Return-to-Zero-Differential Phase Shift Keying). The emission frequency of CW laser is $1480 \mathrm{~nm}$ and output power is $-10 \mathrm{dBm}(0.1 \mathrm{~mW})$.

Signal waveform of NRZ-OOK transmitter is generated by modulating NRZ shaped electrical signal by optical MachZehnder modulator (MZM) [7], [8].

In case of duobinary transmitter, randomly generated data are split to two arms. Using logical NOT component, the logical state of data is inverted in one of the two arms. Signals in both arms are then driven through NRZ modulator driver and modulated using optical dual-drive Mach-Zehnder modulator (DDMZM) [10]. Theory wise, duobinary modulation provide higher spectral efficiency than NRZ based modulation as well as higher tolerance to chromatic dispersion. It uses $R / 2 \mathrm{~Hz}$ bandwidth compared to NRZ-OOK, where $R$ are number of bits transmitted per second. In simple term, duobinary modulation can be described as an amplitude modulation in which the bit stream is manipulated to reduce the bandwidth to overcome inter symbol interference.

NRZ-DPSK modulated signal is generated as a NRZ shaped electric signal modulated by optical phase modulator based on electro-optic effect. The last transmitter is based on CRZDPSK. CRZ encoding technique comes form family of return to zero encoding family. Typical for this encoding technique is that signal frequency of an optical carrier is changed and return to zero is applied. The phase change induced by such a method is 1.5 RAD. That leads to the wide optical spectra and thus worse spectral efficiency. Implementation of CRZ requires another optical modulator. CRZ provides increased performance compared to NRZ. Qualities of CRZ encoded signal comes in count when distance, accumulated chromatic dispersion and intersymbol interference start to increase. This result in higher Q factor and lower BER. Exact implemtation of CRZ-DPSK used in this simulation is following: the original data are first encoded to form two complementary NRZ signals. One signal stream is modulated by MZM. Output of this modulator is used as a carrier wave for optical phase modulator when modulating the second signal stream [11], [12]. Launch power is $-10 \mathrm{dBm}(0.1 \mathrm{mw})$ for all transmitter configurations.

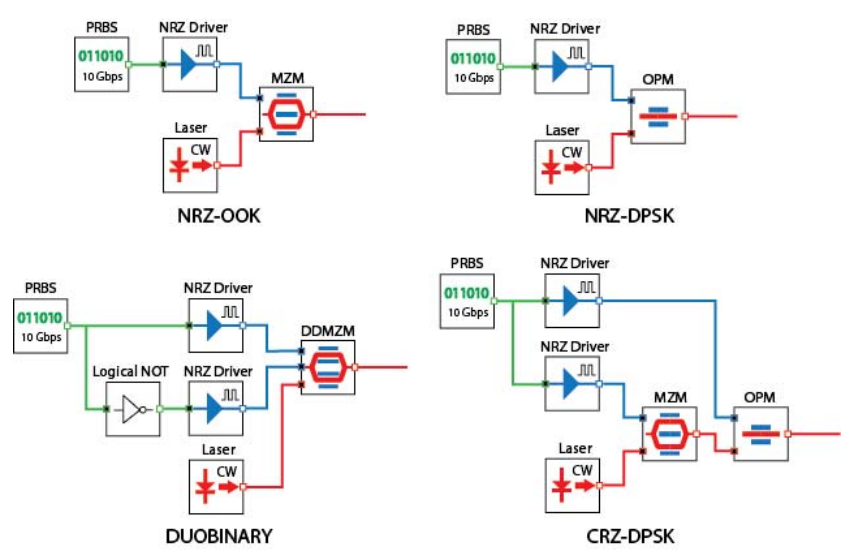

Fig. 4. Transmittres used for $1480 \mathrm{~nm}$ channel

NRZ-OOK modulation is considered to be the industry standard as far as fiber optical systems go. And yet the simulation proves its superb performance. Input and output spectra of 10G-PON using different optical modulations on Internet + VoIP signal stream $(1480 \mathrm{~nm}$ (around $200 \mathrm{THz}))$ is on Fig. 5. The second channel (1550 nm (193.40 THz)) remains the same using 16-QAM-OOK modulation. 


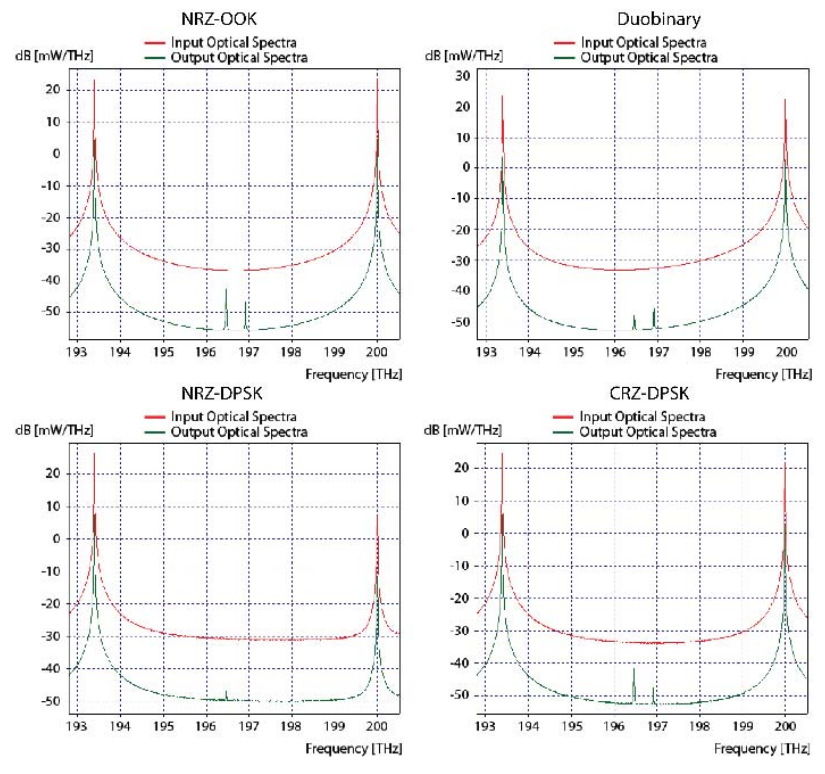

Fig. 5. Input and output optcal spectra of 10G-PON

We can see from the figure above and the Table II below, the power level of NRZ-OOK and duobinary modulation (200 $\mathrm{THz}$ ) is higher than NRZ-DPSK and CRZ-DPSK. NRZ-DPSK modulation offers low signal level $(-14.254 \mathrm{dBm})$ at the output of the proposed ODN. This shortcoming has been removed by implementation of chirped return to zero DPSK $(-12.949 \mathrm{dBm})$. The variation in input and output power is caused due to modulation process. The power levels of input and output spectra are in Table II.

TABLE II. TABLE OF POWER LEVELS

\begin{tabular}{|c|c|c|}
\hline Modulation & $\begin{array}{c}\text { Input Power } \\
\text { Level }\end{array}$ & $\begin{array}{c}\text { Output Power } \\
\text { Level }\end{array}$ \\
\hline NRZ-OOK & $\begin{array}{c}7.001 \mathrm{dBm} \\
0.501 \mathrm{e} 01 \mathrm{~mW}\end{array}$ & $\begin{array}{c}-11.955 \mathrm{dBm} \\
0.638 \mathrm{e}-01 \mathrm{~mW}\end{array}$ \\
\hline Duobinary & $\begin{array}{c}7.006 \mathrm{dBm} \\
0.502 \mathrm{e} 01 \mathrm{~mW}\end{array}$ & $\begin{array}{c}-10.658 \mathrm{dBm} \\
0.859 \mathrm{e}-01 \mathrm{~mW}\end{array}$ \\
\hline NRZ-DPSK & $\begin{array}{c}7.001 \mathrm{dBm} \\
0.501 \mathrm{e} 01 \mathrm{~mW}\end{array}$ & $\begin{array}{c}-14.254 \mathrm{dBm} \\
0.375 \mathrm{e}-01 \mathrm{~mW}\end{array}$ \\
\hline CRZ-DPSK & $\begin{array}{c}7.001 \mathrm{dBm} \\
0.501 \mathrm{e} 01 \mathrm{~mW}\end{array}$ & $\begin{array}{c}-12.949 \mathrm{dBm} \\
0.507 \mathrm{e}-01 \mathrm{~mW}\end{array}$ \\
\hline
\end{tabular}

The end user performance was tested after opto-electronic conversion using eye diagram analyzers. By analyzing eye diagram display we can extract various parameters. Generally, thicker the lines are, bigger the BER (bit error rate) and smaller OSNR (optical signal to noise ratio). OSNR is often expressed via $Q$ factor. $Q$ factor is a function of OSNR and it is in very close relation to BER:

$$
B E R=\frac{1}{2} \operatorname{erfc}\left(\frac{Q}{\sqrt{2}}\right) \approx \frac{1}{\sqrt{2 \pi} Q} \exp \left(-\frac{Q^{2}}{2}\right),
$$

Then, Q factor can be calculated using following equation:

$$
Q=\frac{I_{1}-I_{0}}{\sigma_{1}+\sigma_{2}}
$$

In this equation, $I_{l}$ and $\sigma_{l}$ are mean values and variance output by Gaussian pulse 1 and $I_{0}$ and $\sigma_{0}$ are mean values and variance output by Gaussian pulse 0 .

Eye diagrams of received signals of $1480 \mathrm{~nm}$ channel using various optical modulations are illustrated in Fig. 6. Eyes of NRZ-OOK and duobinary modulation are the most open which predisposes low BER and high OSNR (Q factor) values. The performance of NRZ-DPSK channel is a lot under excepted BER value (1e-012) of modern optical communication systems. Its value is $2.59 \mathrm{e}-003$. This drawback is refined by CRZ-DPSK. All values of BER and Q factor of $1480 \mathrm{~nm}$ channel using above mentioned modulations are in Table III.
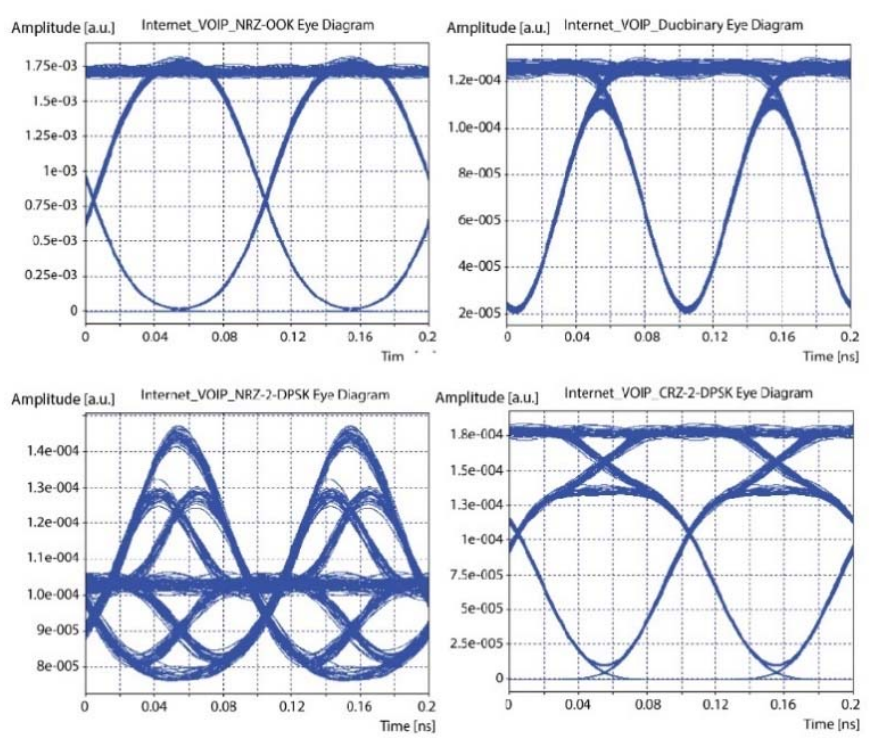

Fig. 6. Eye diagrams of $1480 \mathrm{~nm}$ channel for various optical modulations

The second part of simulation focuses on $1550 \mathrm{~nm}$ channel which is used for broadcasting video (CATV). The configuration of braodcasting video channel is following: Bit rate of randomly generated data is $10 \mathrm{Gbps}$, data are then electricaly modulated by 16-QAM (16-Quadrature Amplitude Modulation) and in the second setup by 64-QAM. Rectangular constelation is considered in both cases. This type of modulation is used also in the real IPTV systems. Electricaly modulated signal is then modulated to an optical carrier (1550 nm) using MZM. The BER and Q factor performance is recorded in Table III. We can see that 16-QAM OOK and 64QAM OOK have very similar values of BER and Q-factor and they both record the values above the limit of aceptance (BER - 1e-012, Q factor - $16.94 \mathrm{~dB}$ ). This shows that even lower quality stream provides sufficient transmission quality over relatively short distnce $(14.708 \mathrm{~km})$. Eye diagrams of received signals are in Fig. 7. 
TABLE III. BER AND Q FACTOR VALUES FOR DIFFERENT OPTICAL MODULATIONS

\begin{tabular}{|c|c|c|c|}
\hline Service & Modulation & BER & Q factor $[\mathbf{d B}]$ \\
\hline $\begin{array}{c}\text { Internet+VoIP } \\
(1480 \mathrm{~nm})\end{array}$ & NRZ-OOK & $1.00 \mathrm{e}-040$ & 34.642 \\
\cline { 2 - 4 } & Duobinary & $1.00 \mathrm{e}-040$ & 33.327 \\
\cline { 2 - 4 } & NRZ-DPSK & $2.59 \mathrm{e}-003$ & 10.086 \\
\cline { 2 - 4 } & CRZ-DPSK & $1.96 \mathrm{e}-016$ & 18.189 \\
\hline \multirow{4}{*}{$\begin{array}{c}\text { Broadcast } \\
\text { Video } \\
(1550 \mathrm{~nm})\end{array}$} & 16-QAM OOK & & \\
\cline { 2 - 4 } & $\mathrm{I}$ & $4.16 \mathrm{e}-020$ & 19.345 \\
\cline { 2 - 4 } & Q & $6.76 \mathrm{e}-021$ & 19.646 \\
\cline { 2 - 4 } & I & $5.93 \mathrm{e}-018$ & 18.639 \\
\cline { 2 - 4 } & $\mathrm{Q}$ & $4.45 \mathrm{e}-020$ & 19.293 \\
\hline
\end{tabular}
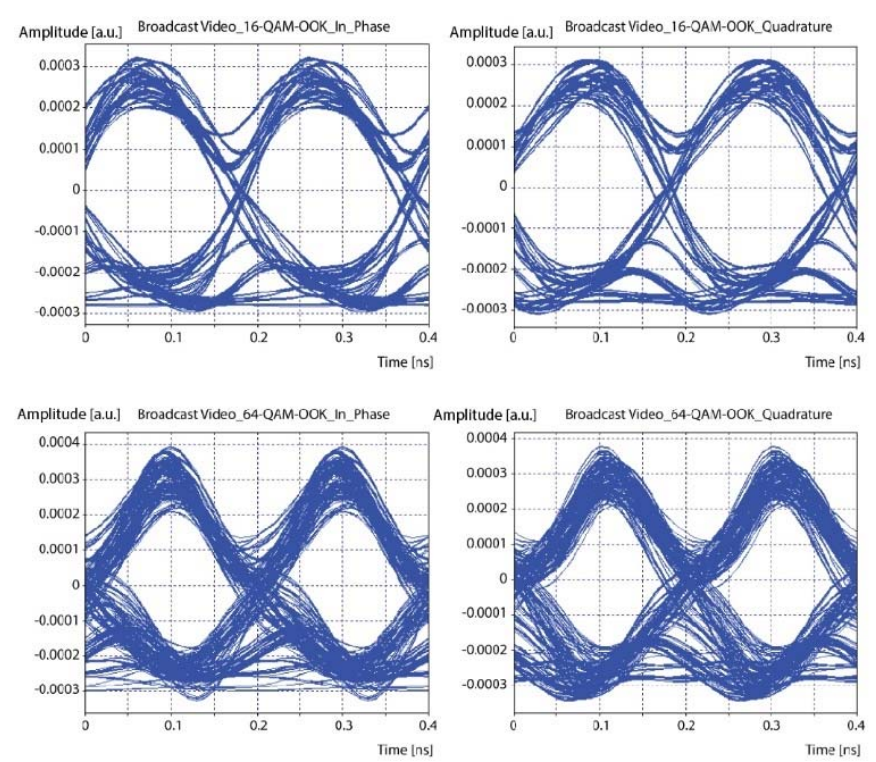

Fig. 7. Eye diagrams of $1550 \mathrm{~nm}$ channel for using 16-QAM-OOK and 64QAM-OOK

Based on the recorded simulation results we can assume that ODN between Košice and Lorinčík is capable of supporting $10 \mathrm{G}-\mathrm{PON}$ system. The most suitable optical modulation for $1480 \mathrm{~nm}$ channel seems to be NRZ-OOK and optical duobinary modulation providing high power level at the end of ODN and desired values of BER and Q factor.

\section{CONCLUSION}

In this paper we investigated 10G-PON FTTH system. The proposed simulation model is based on the real optical distribution network in the city of Košice. This paper presents the possibility of conversion of EPON to $10 \mathrm{G}$-PON. In the simulation we tested various modulation techniques that can be used in 10G-PON. Internet+VoIP channel (1480 nm) shows the best performance using NRZ-OOK and duobinary modulations. Differential phase shift keying does not show convincing performance reaching exceptionally high probability of error. However, the weak performance of NRZ-DPSK can be improved by implementation of CRZ-DSPK. The second channel (1550 nm - video broadcast) shows great performance independently form the modulation technique. The simulation results show that optical distribution network originally build for EPON can easily support next generation PON technologies with high transmission rates as presented in our paper.

\section{ACKNOWLEDGMENT}

This work was supported by following research grants: KEGA 023TUKE-4/2017 and VEGA 1/0772/17.

\section{REFERENCES}

[1] G. P. Agrawal," Fiber-Optic Communications Systems", Third Edition., vol. 3., 471p, 2002.

[2] Spolitis, V. Bobrovs, P. Gavars, and G. Ivanovs, "Comparison of passive chromatic dispersion compensation techniques for long reach dense WDM-PON system," Elektronika ir Elektrotechnika, vol. 122, no. 6, pp. 65-70, 2012.

[3] T. Ivaniga, J. Ružbarský, L’. Ovseník, J. Turán, “Optical Networks FTTx and Reduced Attenuation Balance with Passive Optical Splitter", Carpathian Journal of Electronic and Computer Engineering. Vol. 7, no. 1 (2014), p. 30-35. - ISSN 1844-9689.

[4] M. Al-Quzwini, "Design and Implementation of a Fiber to the Home FTTH Access Network based on GPON," International Journal of Computer Applications, vol. 92, no. 6, pp. 30-42, 2014.

[5] V. Khanaa, K. Mohanta, and T. Saravanan., "Performance analysis of FTTH using GEPON in direct and external modulation," Indian J. Sci. Technol., vol. 6, no. 6, pp. 4848-4852, 2013.

[6] S. Kavitha and G. B. Lakshmy, "Analysis of Linear and Nonlinear Effects in Triple Play Providing WDMPON,” Int. J. Eng. Res. Technol., vol. 3, no. 4, pp. 115-120, 2014.

[7] Rsoft Design GroupL'Inc, "Manual of optsim Models Refernce Volume 1 Sample Mode" 2009, 543p.

[8] J. Ružbarský, J. Turán, and L'. Ovseník, "Different Types of Coding Input Data In Optical Transmission Systems," Carpathian J. Electron. Comput. Eng., vol. 2, pp. 3-6, 2016.

[9] T. Huszaník, L. Ovseník, and J. Turán, "Performance Analysis of Optical Modulation Formats for 10 Gbit / s DWDM System," Carpathian J. Electron. Comput. Eng., vol. 2, no. 10, pp. 3-8, 2017.

[10] T. Ivaniga, L. Ovseník, J. Turán, "The four-channel WDM system using semiconductor optical amplifier", Proceedings of the 26th International Conference Radioelektronika, 2016, Košice, Slovakia, pp. 354-357.

[11] J. A. O'Dowd, S. K. Ibrahim, V. Bessler, and A. D. Ellis, "Investigation of duobinary modulation implementations for use in wavelength switched networks," 2010 12th Int. Conf. Transparent Opt. Networks, Ict. 2010, pp. $1-4,2010$.

[12] P. J. Winzer and R. J. Essiambre, "Advanced Modulation Formats for High-Capacity Optical Transport Networks," J. Light. Technol., vol. 24, no. 12 , pp. 4711-4728, 2006.

\section{ABOUT THE AUTHORS}

Tomáš HUSZANÍK (Ing.) received Ing. (MSc.) degree with

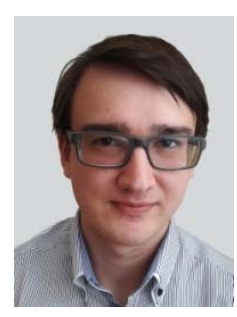
honors from multimedia communication in 2017 at Department of Electronics and Multimedia Communications, Faculty of Electrical Engineering and Informatics of Technical University of Košice. Since September 2017 he has been at Technical University of Košice as $\mathrm{PhD}$. student. His research interest is mainly focused on all optical fiber networks and mitigation and degradation mechanisms in all optical WDM systems. 
Ján TURÁN (Dr.h.c., prof., RNDr., Ing., DrSc.) received Ing.

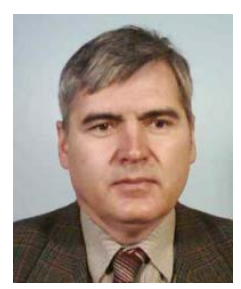

(MSc.) degree in physical engineering with honours from the Czech Technical University, Prague, Czech Republic, in 1974, and RNDr. (MSc.) degree in experimental physics with honours from Charles University, Prague, Czech Republic, in 1980. He received a CSc. (PhD.) and DrSc. degrees in radioelectronics from University of Technology, Košice, Slovakia, in 1983, and 1992, respectively. Since March 1979, he has been at the University of Technology, Košice as Professor for electronics and information technology. His research interests include digital signal processing and fiber optics, communication and sensing.
L’uboš OVSENÍK (doc., Ing., PhD.) received Ing. (MSc.)

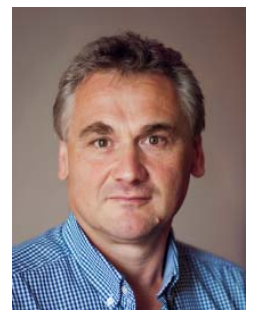
degree in radioelectronics from the University of Technology, Košice, in 1990. $\mathrm{He}$ received $\mathrm{PhD}$. degree in electronics from University of Technology, Košice, Slovakia, in 2002. Since February 1997, he has been at the University of Technology, Košice as Associate Professor for electronics and information technology. His general research interests include optoelectronic, digital signal processing, photonics, fiber optic communications and fiber optic sensors. 